quarters, an impression not fair to him, and as the same accounts may produce the same impression abroad, it seems proper to make the following statement :-

When on the morning of August 17 Prof. Hall showed me his observations, the communication was purely confidential and friendly, and was not made either in the line of duty or because he failed to recognise the significance of his observations, or because any special skill he did not possess wonld aid in interpreting them. I suggested that, from the few measures he had made, it was possible to estimate the time of revolution of the satellite, if the object really were one; and thus ventured the prediction that it would be hidden during most of the following night, but would reappear toward morning near the position in which it was seen the night before. 'The fulfilment of this prediction facilitate'l the esta. blishment of the true character of the object, but, without it, an equally certain hold on the satellite would very soon have been obtained by Prof. Hall alone. The credit of sole discoverer is therefore due to him.

SIMON NEWCOMB

\section{The Satellites of Mars}

I' 1 may interest some of the readers of NATURE to know that one of the recently-discovered satellites of Mars appears to have been certainly seen with the six-f ot reflector at Parsonstown. My assistant writes me on the $\mathrm{I}$ 7th instant :-

"On the 8th instant (before receiving the Washington circular) I suspected very strongly at $I I^{\circ} 45$ P.M, while using the six foct, that a satellite was visible, foilowing the disc, about 1 . diameters. It appears now from the elements that it must have been the outer one. On the $15^{\text {th }}$ instant, at I I 30 P.M., I saw it quite distunctly preceding the planet, however not well enough to measure it, as I lost it again after a couple of minutes, owing to the strong glare of Mars. I, nt night $I$ saw it again, but only by glimpses, twice or three times."

The unfavourable weather prevented the sateilites from being looked for berween the Sch and 15 th instant.

I may add that it seems probable that the satellites might have been measurable on the 15 ih instant with the bright linie micrometer had it not been in the maker's hands. The low meridian altitude of the planet $\left(25^{\circ}\right.$ at Parsonstown as compared with $40^{\circ}$ at Washington) is of course a serious drawback to obser vations at the former place.

ROSSE

Yorkshire, Sentember 20

THE weather in this neighbourhood has been very unfavour able for observation ever since the announcement of the discovery of two satellites of Mars. Last night, however (about 9.30), during little more than half-an-hour's interval of clear sky, the air boing extremely steady, and the planet beautifully defined, succeeded in seeing the outer satellite of the two. With the full aperture of my I 8 -inch silvered-glass equatorial reflector, and an ordinary achromatic eye-piece with a bar across the field hiding the planet, the satellite was but glimpsed occasionally; with a single double-concave lens (power about I80) it was visinle, in spite of the brilliant light of the planet. Had I no known its exact position, however, I question whether I should have seen it at all. It is a most clifficult ohject.

Stretton Rectory, Hereford, September I9

\section{A Good Suggestion}

THE approaching meeting in London of librarians representing the most important English, and, I believe, fortign, collections of books, makes the present a suitable time to offer suggestions as to the management of such collections.

It has long seemed to me that an improvement might be made of a very simple nature, but capable of greatly increasing the working value of reference libraries, especially those of the first rank; namely, to provide, somewhat as foliows, for their being consulted by those who cannot personally visit them.

Suppose that the autborities of such an institution as the British Museum or the Bodleian designate certain persons, not paid officers of the library, but known to its directors as welleducated, trustworthy, and acquainted with the resources of the particular library; publishing the names and addresses of these gentlemen as willing, and believed to be competent, to undertake researches amongst the books for those who may write to them from a distance; the official authorities assuming no actual res?onsibility for the work so done, but merely recommending the persons to do it; publishing at the same time a definite statement of the payment expected per day or hour by these persons.

Often when one would desire to consult a great public library in a foreign land, or in a distant part of one's own country, nothing short of a personal visit would be of use, but in very many cases it would be quite possible to obtain all that one desired by a simple business-like correspondence with a proper agent. Sometimes the question is merely whether such or such a book exists in the library, with perhaps an accurate copy of its title; sometimes a special reference to a single page in an old and scarce scientific journal or set of transactions is to be verified; sometimes a few paragraphs are to be copied in the exact words of the author; sometimes a name, date, or number is to be sought out; sometimes a larger amourt of work would be needed, but so definitely shaped out that instructions in writing could easily be given for it to an intelligent person on the spot. As it is, the consulting of such a distant library in person is often simply impossible, and even when possible, often involves such expense and delay as to make themselves serionsly felt ; whereas by the plan proposed, the object in view might often be attained at a cost of time and money al together trifling. In my ow a very small experience $I$ once found it necessary to travel some 700 miles, losing three days, and spending abont $7 l$., in wier to refer to a book for about ten minutes, while directions for msking the same search could have easily been put upon half a sheet of notepaper, and carrying them ont would have occupied a person living in the city in which the library was situated altogether not more than an hour or an lour and-a-tialf.

In the neighbourhood of almost every large library competent men might reidily be found to undertake such work as is suggested, and to whom the opportunity of increasing their income, or probably in time earning from this source alone a satisfactory income, would be welcome. The plan would admit of being carried out upon a small or an extencied scale; a library of the third or fourth class might afford a field for a singte man only, while one of the first class would be likely gradially to enlist the services of a number; if this were so suib-division of labour would be desirable, one person undertaking researches in natural history, another in mathemstics, physics, or chemistry, another in classical learning, \&rc.

While such work could not properly be done by the regular offcers of a public library, it would be important that the private individuals who were to enter upon it shotld have the approval of, and should be recommended by, the libray authorities, who might also very properly fix the rate of payment, recommending only those who were willing to accept the rules lixid down.

This plan has at least the merit that it might be tested with very little trouble, risk, or disturbance of exising arrangements. I believe that even in England with great libraries situated at comparatively moderate distances from almost every one in the kingdom, it would prove a great convenience; to persons piaced as are those wholive here in America, with nolibrary of the first rank on this side of the ocean, and with hundreds of miles often separating one from the larger of even those libraries which do here exist, the boon of access by letter to the grea:est collections of the world would be inestimable. It would be in a new direction, and a noble one, carrying out the tendency of the most modern civilisation which looks to placing, as far as possible, the resources of the whole earth within the reach of him who lives at any one spot upon its surface

University of Virginia, Setember 5

Some of the Troubles of Join O'Toole respecting Potential inergy ${ }^{1}$

II.

\section{B.-Potential E., as meaning "energy related to Potential Fronctions."}

WE now pass to the second meaning of "potential E." It happens, by a most singular and unfortunate coincidence, that this class of $\mathrm{E}$. can very well be called by that title for a reason quite distinct from that which we have been deprecating. The idea of the potential function, or brieliy, potential, was first formed and thus named by Green. It has no reference whatever to existing in possibility; it is concerned with present potency or power; and it happens that potential E. of unit of mass may 